\title{
O sofrimento psíquico contemporâneo no imaginário coletivo de estudantes de Psicologia
}

\author{
Heloisa Aguetoni Cambuí' \\ Carmen Maria Bueno Neme \\ Universidade Estadual Paulista, Bauru - SP - Brasil
}

\begin{abstract}
Resumo: As profundas transformações socioculturais pelas quais atravessa o mundo têm sido acompanhadas de novas configurações subjetivas e manifestações de sofrimento psíquico, cujo impacto e ressonância na clínica psicológica exigem compreensão e manejos singulares. O objetivo deste estudo foi investigar o imaginário coletivo de estudantes de Psicologia acerca do sofrimento psíquico contemporâneo. À luz do método psicanalítico, esta investigação utilizou o procedimento de desenhos-estórias com tema em entrevista grupal. $O$ conjunto das produções dos desenhos-estórias, com base nas narrativas interativas redigidas após cada entrevista, foi interpretativamente analisado e permitiu a apreensão dos seguintes campos de sentido afetivo-emocional: "Solidão", "Ensaio sobre o sofrimento", "Agonias do não-ser", "Encontro humano com o sofrimento", "Fuga: a grande defesa", "Não vivido", “Desesperança humana" e "Sofrimento multifacetado". O conjunto das análises permitiu a apreensão de um imaginário coletivo no qual o sofrimento atual é constituído, principalmente, por sensações de solidão, desamparo, futilidade, inautenticidade e vazio existencial.
\end{abstract}

Palavras-chave: sofrimento; desenho; imaginário coletivo; psicanálise; Winnicott.

\section{THE CONTEMPORARY PSYCHIC SUFFERING IN THE COLLECTIVE IMAGINARY OF PSYCHOLOGY STUDENTS}

\begin{abstract}
Profound socio-cultural transformations that the world has undergone have been followed by new subjective configurations and manifestations of psychic suffering, whose impact and resonance in the psychology clinic, demand especial understanding and management. The aim of this study was to investigate the collective imaginary of Psychology students about contemporary psychic suffering. In the light of the psychoanalytic method, this research utilized the procedure of drawings-stories with theme in group interview. The set of productions of the drawings-stories, based on the psychoanalytic narratives written after each group interview, was interpretatively analyzed and allowed the apprehension of the following fields of affective-emotional meaning: "Loneliness", "Essays on suffering", "Agony of non-being", "Human contact with suffering", "Avoidance: the great defense", "Non lived lives", "Human despair" and "Multifacetated suffering". The set of analyses allowed the understanding of a collective imaginary in which suffering, that occurs nowadays, consists mainly of feelings of loneliness, forsaking, uselessness, spuriousness and existential void.
\end{abstract}

Keywords: suffering; drawing; collective imaginary; psychoanalysis; Winnicott.

1 Endereço para correspondência: Heloisa Aguetoni Cambuí, Rua João Fiuza, 136, Vila Fiuza - Assis - SP Brasil. CEP: 19814-520. E-mail: heloisacambui@yahoo.com.br. 


\begin{abstract}
Resumen: Las profundas transformaciones socio-culturales por las cuales atraviesa el mundo se han visto acompañadas de nuevas configuraciones subjetivas y manifestaciones de sufrimiento psicológico cuyo impacto y resonancia en psicología clínica, requieren comprensión y manejos especiales. El objetivo de este estudio fue investigar el imaginario colectivo de los estudiantes de Psicología acerca de sufrimiento psicológico contemporáneo. De acuerdo con el método psicoanalítico esta investigación utilizó el procedimiento dibujos-historias con tema en entrevista grupal. El conjunto de las producciones de dibujos-historias, baseado en narraciones psicoanalíticas escritos después de cada entrevista, se analizó interpretativamente y permitió accesar los siguientes campos de sentido afectivo-emocional: "La soledad", "Ensayo sobre el sufrimiento", "Agonías del no-ser", "Encuentro humano con el sufrimiento", "Escape: una gran defensa", "Vidas no vividas “, "Desesperación humana” y "Sufrimiento multifacético”. El conjunto de análisis permitió accesar un imaginario colectivo en el cual el sufrimiento actual se constituye principalmente por sentimientos de soledad, impotencia, inutilidad, falta de autenticidad y vacío existencial.
\end{abstract}

Palabras clave: sufrimiento; dibujo; imaginario colectivo; psicoanalise; Winnicott.

As profundas transformações socioculturais pelas quais atravessa o mundo incidem inevitavelmente sobre o campo das subjetividades, cujo impacto pode acarretar novas configurações subjetivas, modalidades de sofrimento psíquico e demandas clínicas. Observa-se uma condição contemporânea na qual é possível identificar grande sofrimento humano devido às condições singulares do mundo atual. Os novos modos de sofrimento refletem-se na clínica psicoterápica, cujo manejo exige peculiaridades compreensivas na tentativa de possibilitar sua sustentação.

Muitas das mudanças significativas do presente incidem sobre a vida e a existência humana, apresentando-se associadas a novas fontes de sofrimento emocional e, em consequência, a novas manifestações psicopatológicas (Campuzano, 2009; Pires Caniato \& Vargas Nascimento, 2010). Ao se considerar a subjetividade humana como constituída por articulações culturais, históricas e sociais e, ainda, intimamente relacionada a condições individuais do sujeito, questiona-se, na atualidade, a possível repercussão, nessa constituição, de diferentes aspectos decorrentes da vigência de uma nova ordem social.

Ao situar o objeto de investigação nas configurações do mal-estar contemporâneo, Bauman (1998) esclarece que, diferentemente do mal-estar moderno que estava relacionado à repressão, o mal-estar atual está associado ao excesso e à liberdade, que acabam por ocasionar a fragmentação temporal, a desvalorização da historicidade e o domínio da intensidade sobre o sentido da experiência. Por sua vez, Birman (2013) ressalta que modalidades anteriores de sofrimento, centradas em conflitos intrapsíquicos, cederam lugar, na atualidade, a dimensões de mal-estar que incidem nos registros do corpo, da ação e do sentimento. Nesse sentido, o fenômeno da globalização e as consequentes modificações por ele geradas têm conduzido à necessidade de compreender essas novas formas de sofrimento psíquico que não se restringem apenas a uma inquietação, mas também denunciam processos de fragmentação do ser, a constituição de configurações subjetivas fundamentalmente frágeis e a precariedade da 
experiência subjetiva (Libermann, 2010; Magdaleno, 2010). Evidenciam-se, portanto, modalidades de dores psíquicas direcionadas aos registros do corpo e das condutas, as quais aludem à impossibilidade da existência real no mundo e expõem a perda ou a impossibilidade da experiência pessoal.

As dimensões referentes à natureza do sofrimento psíquico envolvem modalidades complexas que perpassam a discussão de elementos constitutivos do sujeito, bem como as concepções de saúde e de adoecimento psíquico. Para Winnicott (1975), os aspectos saudáveis do porvir da natureza humana estão relacionados à capacidade de existir e de se sentir real. A partir do viés da saúde, concebe-se a experiência de sofrimento psíquico como um fenômeno singular, existencial e essencialmente humano que consiste na impossibilidade de se sentir verdadeiramente vivo e real. Por conseguinte, o campo da psicopatologia remete-se ao conjunto de ideias e concepções sobre a potencialidade sofredora humana (Aiello-Vaisberg \& Medeiros, 2010).

A partir da constante reflexão sobre o sofrimento humano e da tentativa de apreensão das modalidades de sofrimento presentes na atualidade, este estudo se desenvolveu sob a perspectiva psicanalítica, com o objetivo de investigar o imaginário coletivo de estudantes de Psicologia sobre o sofrimento psíquico atual. Considera-se relevante identificar os sentidos subjetivos acerca do sofrimento psíquico contemporâneo no imaginário dos estudantes de Psicologia. Esses sentidos comporão o contexto intersubjetivo clínico no futuro exercício profissional desses estudantes, que, de diferentes formas, devem refletir sobre as novas manifestações da subjetividade humana.

\section{Método}

O presente estudo desenvolveu-se sob a perspectiva intersubjetiva psicanalítica, posto que a psicanálise, como método investigativo e referencial teórico, revela-se como um instrumento potencial para a compreensão dos modos de funcionamento psíquico em contexto intersubjetivo. Tendo em vista a apreensão do imaginário coletivo dos estudantes de Psicologia sobre o sofrimento psíquico atual, direcionou-se a investigação das condutas humanas que se expressam na área simbólica com base no conceito blegeriano de imaginário coletivo, que corresponde à manifestação simbólica e concreta das subjetividades grupais que emergem em contextos intersubjetivos.

Segundo Bleger (1989), os fenômenos humanos são manifestações ou condutas dotadas de sentido emocional, que podem aparecer de modo simbólico, corporal e sob a forma de atuação sobre o âmbito individual ou coletivo. A conduta é um fenômeno complexo, e sua manifestação coexiste nessas três áreas, vinculando-se também à estória de vida pessoal e ao contexto social, político e cultural. Alinhados aos pressupostos blegerianos e às pesquisas de Aiello-Vaisberg e seu grupo, que visam investigar os campos do imaginário em diferentes grupos sociais (Pontes, Barcelos, Tachibana, \& Aiello-Vaisberg, 2010), o “imaginário coletivo" é apreendido como um complexo 
ideoafetivo, ou seja, como conduta que ocorre no campo da intersubjetividade e que preconiza o substrato afetivo-emocional das manifestações simbólicas que influenciam as ações no mundo.

\section{Instrumentos}

O acesso a conteúdos não conscientes e a captação do imaginário coletivo por meio do uso do Procedimento de Desenhos-Estórias com Tema (PDE-T) foram oportunizados pela criação de um espaço apropriado para a expressão subjetiva e realizados em um enquadre diferenciado, denominado entrevista grupal para abordagem da pessoalidade coletiva (Aiello-Vaisberg \& Machado 2005). Inspirada nas consultas terapêuticas de Winnicott (1994b), a entrevista tem um enquadre transicional e intersubjetivo, e se caracteriza por seus aspectos lúdicos, com o uso de um recurso mediador-dialógico baseado no Jogo do Rabisco.

\section{Participantes}

Para a aplicação do PDE-T em entrevista grupal, participaram dez alunos ingressantes, do primeiro ano, de um curso de graduação em Psicologia do interior paulista e sete alunos do quinto ano, em conclusão do mesmo curso, que se dispuseram a colaborar, independentemente de gênero ou idade. Tal escolha justifica-se pelo fato de que o estudante de Psicologia realizou uma opção profissional no campo das ciências humanas e, dessa forma, imbricado nas complexas questões humanas e dos perspectivos campos de atuação, pode ser potencialmente mais sensível ao tema investigado.

\section{Procedimentos de coleta e análise dos dados}

Foi realizada, para ambos os grupos de participantes, uma entrevista grupal mediada pelo uso do instrumento mediador-dialógico. Os participantes foram convidados a fazer uso individual, em ambiente coletivo, do PDE-T de acordo com a proposta: "Desenhe uma pessoa que se encontra em sofrimento psíquico na atualidade". Foi também solicitado que escrevessem uma estória associada ao desenho e a intitulassem. Após a realização do desenho-estória, abriu-se um espaço no qual os participantes pudessem se sentir à vontade para se expor, e, em enquadre clínico diferenciado, a psicóloga-pesquisadora fez comentários referentes ao tema e ofereceu acolhimento às demandas pessoais emergentes.

O procedimento utilizado e a adoção do método psicanalítico na pesquisa sustentam-se criteriosamente em etapas descritas pela literatura (Aiello-Vaisberg \& Machado, 2005). Primeiramente, estabelece-se a configuração do campo experiencial inter-humano pela via do enquadre lúdico-investigativo; posteriormente, procede-se à elaboração da narrativa; e, por fim, realiza-se o compartilhamento do material com outros pesquisadores para sua análise. De acordo com esses 
procedimentos, após a realização de cada entrevista grupal, a pesquisadora elaborou um texto narrativo do acontecer clínico. Sob a forma de narrativas psicanalíticas, registrou-se a experiência clínica, incluindo as impressões despertadas, a articulação dos diálogos, as associações e os sentimentos contratransferenciais, de modo a revelar a vivência do encontro, a partir da visão da pesquisadora. Posteriormente, com o objetivo de promover reflexões singulares e a emersão de novos campos de sentido, os desenhos-estória foram compartilhados com a orientadora responsável e com outra psicóloga-pesquisadora com conhecimento e experiência com o uso desse instrumento. Nesse terceiro momento, o material derivado da entrevista foi psicanaliticamente analisado, com base nas narrativas, buscando apreender os campos psicológicos, segundo os quais se organiza o imaginário coletivo (Herrmann, 1979). Assim, ao entrarem em contato com o material coletado, as psicólogas-pesquisadoras, a partir do uso da associação livre e da atenção equiflutuante, adotaram as condições metodológicas indicadas por Herrmann (1979): "deixar que surja", "tomar em consideração" e "completar o desenho".

Com base no método psicanalítico, apreenderam-se campos de sentido afetivo-emocional relacionados ao tema investigado, que posteriormente foram interpretados à luz da psicanálise winnicottiana. Esclarece-se que, em consonância ao pensamento de Bleger (1989), embora cada desenho-estória tenha sido produzido individualmente, o material foi analisado como conjunto de associações emergentes de um psiquismo grupal, referente tanto ao grupo de alunos ingressos quanto ao grupo de alunos em formação. Selecionaram-se, para as finalidades do presente trabalho, os desenhos e as estória de cada campo de sentido em ambos os grupos de participantes, julgados pelas pesquisadoras como os mais imediatamente representativos dos campos de sentido descritos.

\section{Resultados e discussões}

A seguir, apresentam-se os campos psicológicos detectados nos dois grupos de participantes: $A$ (composto por alunos ingressantes) e B (composto por alunos em conclusão de curso). Esses campos abarcam as respectivas concepções dos estudantes de Psicologia.

\section{Os campos do imaginário no grupo A}

\section{Campo "Solidão"}

No imaginário coletivo desse grupo, emergiu, de forma predominante, o campo "Solidão", em que o sofrimento psíquico contemporâneo é constituído essencialmente pelas sensações de solidão e desamparo decorrentes das idiossincrasias do mundo atual. Esse campo de sentido afetivo-emocional compõe-se pela apreensão de que o sofrimento psíquico atual articula-se à vivência de solidão em meio à multidão. 
Como mostra a Figura 1, as produções imaginativas denunciam antíteses e paradoxos presentes no mundo atual, em que o sujeito sente-se demasiadamente solitário em um mundo superpopuloso.

\section{Figura I. Desenho-Estória de Girassol que compõe o campo "Solidão"}

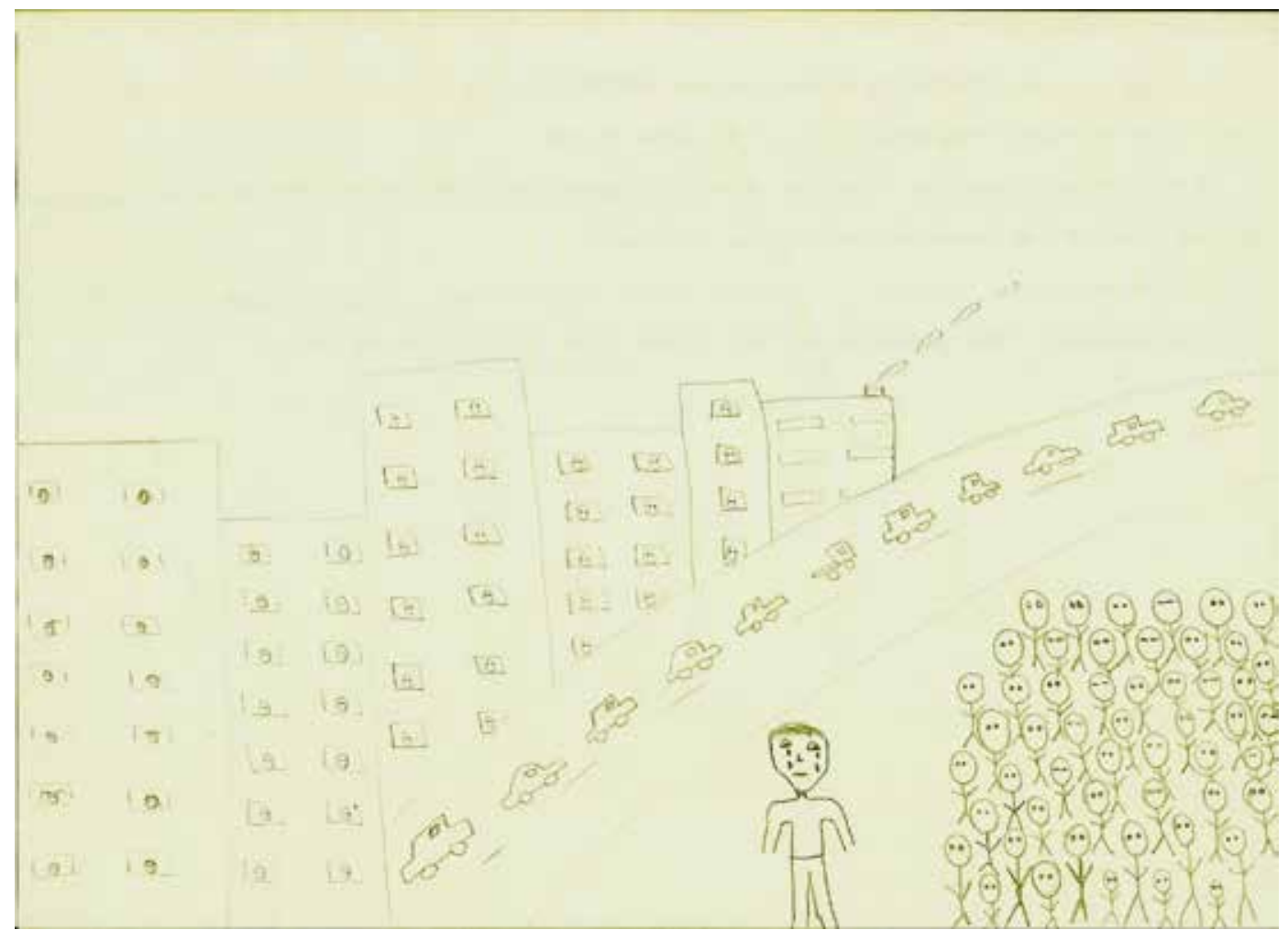

Fonte: Cambuí, 2013, p. 99.

Esse grupo de produções imaginativas dispôs-se ao redor dos organizadores lógico-emocionais de que a fluidez e a instantaneidade do mundo globalizado levam à instabilidade das relações, à dificuldade de constituição e manutenção de grupos sociais, ao empobrecimento dos laços afetivos e, ainda, à ausência de referenciais e segurança. Nota-se, na atualidade, a presença de subjetividades caracterizadas por processos constitutivos fragmentários, que denunciam novos modos de sofrimento humano e modelos de vida centrados na precariedade, na fragilidade, no esvaziamento e na vulnerabilidade do eu (Dantas, 2009). Em consonância com Aiello-Vaisberg e Medeiros (2010), evidencia-se, nesse campo, o predomínio de expressões subjetivas relacionadas ao fenômeno de hipersolicitação pessoal e ao excesso de estímulos e ofertas fugidias e inalcançáveis, que despertam o sentimento de insuficiência, desenraizamento, solidão e desamparo, como corolários do sofrimento psíquico atual. 
Ainda que vivesse rodeado de pessoas, imerso no caos da vida na cidade grande, envolto por carros, construções, máquinas, gente... ele sentia-se só. O sofrimento psicológico vinha da solidão, de sentir-se microscopicamente pequeno comparado ao mundo, de sentir-se perdido na multidão... Ele só precisava conversar, precisava ouvir e ser ouvido... Mas a cidade não pode parar, as máquinas não podem parar, as pessoas não têm tempo de parar (Girassol).

No fragmento da estória de Girassol, evidencia-se que, no mundo ocidental contemporâneo, em meio ao aglomerado de pessoas, as características pessoais se volatilizam e tornam-se indiferenciadas em meio à multidão, indicando a possível homogeneização das subjetividades. Tal como discutido por Menezes (2008), esses dados corroboram a incidência reiterada, na atualidade, de experiências de desencontros, solidão, descrença, fracasso, abandono e desamparo.

Com base nas manifestações subjetivas captadas nesse campo de sentido, pode-se estabelecer um paralelo com as contribuições de Dantas (2009), visto que as relações inter-humanas atuais configuram-se essencialmente pela virtualidade, pelo distanciamento afetivo e pela falsificação do real. Outro aspecto relevante que compõe esse campo vivencial consiste na configuração do sofrimento humano decorrente do estabelecimento de relações interpessoais mediadas pelos recursos tecnológicos, os quais amplificam as sensações de isolamento e solidão, e, ainda, concorrem para o distanciamento afetivo e para a falsificação do real. Nesse sentido, infere-se que tais produções imaginativas condizem com as questões expostas pelos pensadores da atualidade que debatem as interferências da tecnologia no acontecer humano.

Inserido nesse amplo campo, encontra-se o subcampo "Ensaio sobre o sofrimento", cuja aproximação ao sofrimento, pelos participantes, foi realizada a partir de ensaios e tentativas, por meio da mobilização de artifícios defensivos que revelam dificuldades de contato com a problemática abordada. No fragmento "Nos escombros do homem, de fato, tudo isso é falso. Mas que mal há em viver sob uma superficialidade deleitosa?" (Azálea), observa-se que a característica principal desse subcampo é a abordagem do sofrimento sob um aparato em que prevalece a manifestação de recursos como a racionalização, a intelectualização e a superficialidade, como meios falhos de aproximação ao sofrimento. $O$ deparar-se com o sofrimento do outro, que remete às próprias angústias pessoais, pode mobilizar situações inquietantes e, em decorrência, levar o sujeito a recorrer a movimentos defensivos, preservando-se, assim, por meio de posturas intelectualizadas e pautadas essencialmente em abordagens encobertas e superficiais.

\section{Campo "Agonias do não-ser"}

Esse campo de sentido afetivo-emocional congrega produções que articulam o sofrimento à ordem das angústias impensáveis, descritas por Winnicott (1994a), que perpassam indivíduos que não alcançaram a constituição psíquica e vivem em estado de inexistência humana. As manifestações subjetivas presentes nesse campo configuram o sofrimento por meio de experiências aflitivas, desintegradoras e invasivas de pessoas 
que jamais alcançaram a experiência de existência pessoal. Com base nesse subcampo, destaca-se a incidência atual de subjetividades contemporâneas acometidas pela vivência intermitente e extrema do sofrimento, sendo configuradas por dores intoleráveis, indescritivelmente agônicas, que remetem a uma dimensão inimaginável de ansiedade de aniquilamento.

Esse grupo de produções imaginativas define-se, também, pelo sentido subjetivo de que falhas ambientais precoces podem resultar em fraturas na continuidade de ser, uma vez que podem levar o ser humano imaturo a elaborar movimentos defensivos que interferem na possibilidade do vir a ser e na possibilidade de se sentir vivo e real.

Destituído de forma, tudo lhe era impessoal, insípido e torturante. Olhava as paredes de sua casa; eram tão frias, tal qual seu coração sucumbido a um temor inexplicável. Vivia uma semi-vida, uma experiência trivial e banal: isso o assustava, atormentava-o de forma cruel e desgastante. Olhava-se ao espelho tentando encarar o âmago de sua existência, tentava chorar, mas essa catarse úmida não acontecia, tentava desviar os olhos de seu reflexo, de sua própria vida, não queria mais confrontar os fantasmas dantescos que Ihe sussurravam aos ouvidos. Sussurravam-Ihe segredos destruidores, revelações ignóbeis e molestadoras. Percebia agora a vida oca que vivera, via uma morte insignificante pela frente, descobria que não era único, não era um, pertencia a uma massa, a um coletivo que caminhava rumo ao abate, ao carrasco! [...] (Cravo).

Na estória de Cravo, notam-se manifestações imaginárias de violação do self e destituição da vida do indivíduo, visto que este fora encerrado em sua própria (in)existência. O sofrimento revela-se como um temor inexplicável e assustador representado pelas angústias "molestadoras" presentes. Nota-se a presença de uma "semi-vida", configurada como "impessoal"; uma existência inabitada e submetida às imposições e aos modelos sociais. As concepções subjetivas presentes indicam a organização de um falso self como recurso defensivo contra o ambiente invasivo e permissivo. O desenvolvimento do falso self é uma organização defensiva bem-sucedida, direcionada a proteger o núcleo do self verdadeiro e a evitar o mergulho nas agonias impensáveis. $O$ falso self se constrói com base na submissão, e sua instauração resulta em sensações de inutilidade e irrealidade (Winnicott, 2000).

\section{Campo "Encontro humano com o sofrimento"}

Esse campo de sentido afetivo-emocional apresenta expressões imaginárias de contato amadurecido e humano com o sofrimento. Articulam-se manifestações integradas e reais sobre o sofrimento por meio de experiências de vida, alicerçadas no acolhimento da criatura sofredora. Evidencia-se, na Figura 2, a representação do sofrimento como algo propriamente humano, além de outros aspectos importantes referentes à carência constitutiva desse ser, à fragilidade e à vulnerabilidade perante um outro que possa reconhecê-lo em sua humanidade, por meio de um manejo sustentador e esperançoso. 


\section{Figura 2. Desenho-Estória de Magnólia que compõe o campo "Encontro humano com o sofrimento"}

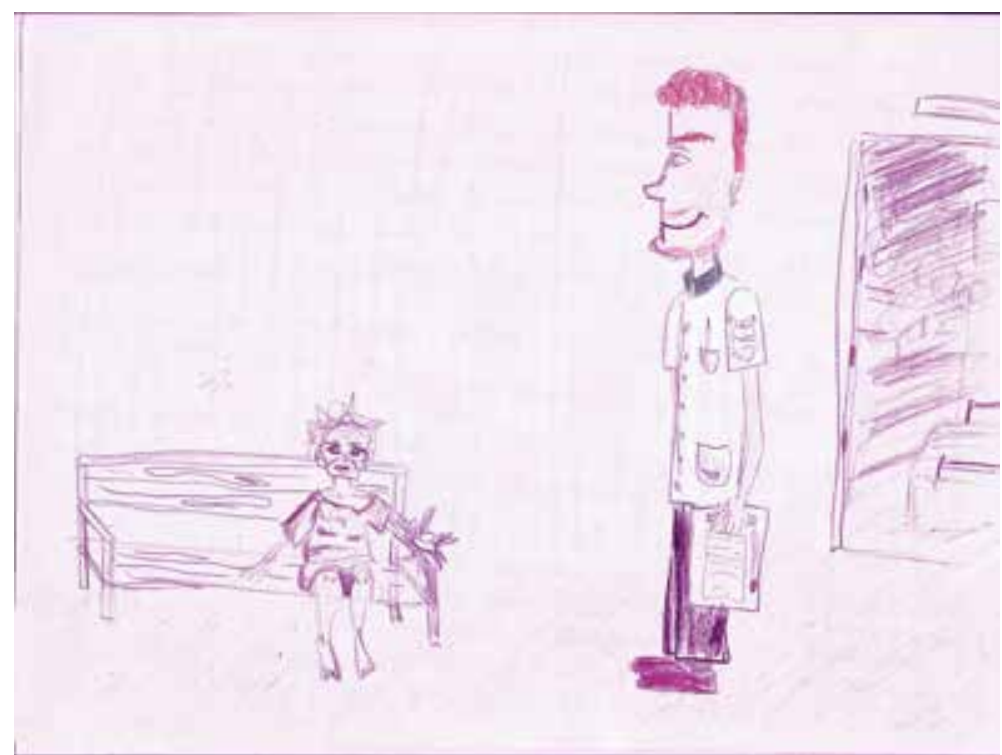

Fonte: Cambuí, 2013, p. II4.

Admite-se, nesse campo, a possibilidade de um encontro sensível com o sofrimento por indivíduos que adquiriram a capacidade de se preocupar e alcançaram o amadurecimento pessoal integrado, cuja disponibilidade interna remete a uma forma saudável de se preocupar e lidar humanamente com o sofrimento. Evidenciam-se, portanto, sentidos subjetivos que preconizam condutas humanas sustentadas em encontros e relacionamentos inter-humanos singulares e reais, sendo estas consideradas necessárias e indicativas de saúde emocional do profissional que atua na clínica da contemporaneidade (Aiello-Vaisberg \& Machado, 2003).

\section{Os campos do imaginário no grupo B}

Campo "Fuga: a grande defesa"

No imaginário coletivo do grupo de estudantes em conclusão de curso, emergiu o campo "Fuga: a grande defesa" que comporta uma reprodução copiosa e impessoal, a qual evidencia a dificuldade e a impossibilidade de representação do sofrimento psíquico atual. Esse campo de sentido é regido segundo os organizadores lógico-emocionais de que o contato com o sofrimento pode ser algo tão perturbador que impossibilita sua representação. A possibilidade de se deparar com o sofrimento e com o despertar de questões pessoais levou à mobilização de defesas para afugentar sentimentos angustiantes, com os quais, naquele momento, o indivíduo não era capaz de lidar. $O$ desenho elaborado reproduz a pintura $O$ grito, de Edvard Munch. A figura de 
olhar longínquo conduz à associação do grito com o clamor do próprio participante, que reivindica a retomada de seu potencial criativo, desapegado de uma postura submissa, posto que também se encontra inserido numa sociedade fragilizada.

\section{Campo "Não-vivido"}

O campo "Não-vivido" predomina sobre os demais no grupo B e organiza-se ao redor dos organizadores lógico-emocionais de que o sofrimento condiz com uma representação falseada da realidade e da própria experiência, em que os sentimentos de futilidade e submissão são permanentes. Evidencia-se, na Figura 3, a presença de expressões subjetivas que congregam a existência de vidas irreais, superficiais e espectrais, associadas às sensações de inutilidade, inautenticidade e vazio existencial. Esse campo psicológico-vivencial admite a crença de que o sofrimento configura-se a partir da instauração de um falso self, que conduz à percepção obscura, externalizada e implantada do ambiente, assim como estabelece a incapacidade e a dificuldade de relacionamentos inter-humanos significativos e espontâneos. Destaca-se, nesse campo, outro aspecto importante que associa o uso de drogas lícitas e ilícitas como recurso para a fuga do sofrimento. Aielo-Vaisberg e Machado (2003, pp. 19-20), ao discutirem sobre as modalidade de sofrimento emergentes na atualidade, afirmam que a demanda clínica em ascensão compreende a manifestação de angústias profundas que comprometem a qualidade de vida e remetem "à falta de sentido da vida, aos sentimentos de futilidade da existência, às depressões, ao pânico, à violência e à drogadição".

\section{Figura 3. Desenho-Estória de Lírio que compõe o campo “Não-vivido"}


As manifestações subjetivas desses participantes alinham-se a fenômenos presentes na sociedade ocidental contemporânea, impregnada de sentimentos de vazio associados à submissão, à vivencia de um falso self e à futilidade de viver. Ao se defenderem, os sujeitos estabelecem convivências empobrecidas e inautênticas, de modo que a imagem idealizada ofertada subjuga-se à existência do ser, ocultando aspectos dissociativos e de impotência.

Do campo "Não-vivido", emergiu o subcampo "Desesperança humana", no qual impera um sentimento negativo de falta de esperança na capacidade de retomada dos aspectos saudáveis do ser humano que se encontra em sofrimento. As expressões subjetivas comportam, sobretudo, expectativas frustrantes e impotentes em relação ao acolhimento e aos cuidados disponibilizados. Esse subcampo de sentido afetivo-emocional é regido pela imperiosa descrença no ser humano. Reúne manifestações imaginativas que configuram o sofrimento como algo estruturado e definitivo, que se caracteriza como um fardo eterno e solitário. Prevalecem expressões imaginativas que abarcam o julgamento e a culpabilização das pessoas que sofrem, e, em decorrência, predomina uma dimensão relativa à ausência de esperança e de cura para esse sofrimento, como ilustrado na Figura 4.

Figura 4. Desenho-Estória de Íris que compõe o subcampo “Desesperança humana"

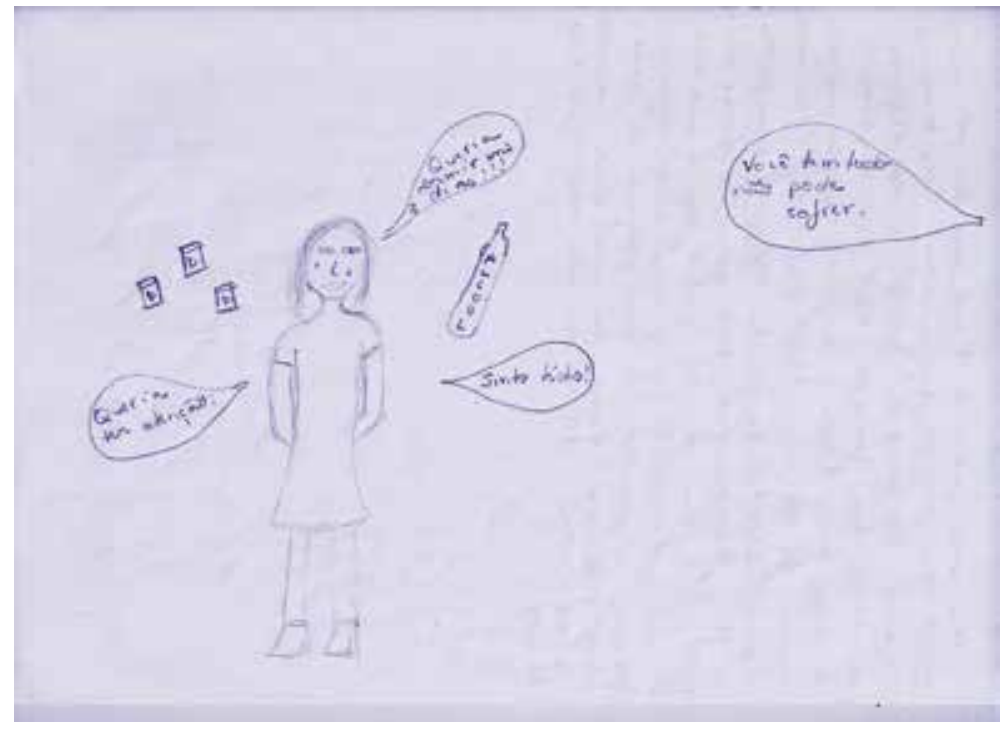

Fonte: Cambuí, 20I3, p. 124.

Esse subcampo conduz à necessidade de reflexões e de reposicionamentos profissionais no exercício da prática clínica. Reconhece-se, na clínica da atualidade, a premência de manejos clínicos constituídos pelo encontro inter-humano devotado que possibilite o reconhecimento da coexistência e da capacidade transformadora do si mesmo, bem como da retomada da continuidade de ser em uma esfera digna de ser 
vivida. Compreende-se que, somente inteirado das próprias dificuldades e angústias, o psicoterapeuta será capaz de reconhecer a singularidade do outro e de manter a esperança de que ele possa emergir do caos (Saad, 2011).

\section{Campo "Sofrimento multifacetado"}

Esse campo de sentido afetivo-emocional organiza-se ao redor de expressões subjetivas que retratam o sofrimento de forma confusa e polarizada, considerando-o como resultante das atuais configurações sociais e, contraditoriamente, definindo-o como inerente à condição humana. Observa-se, no seguinte fragmento, a presença de elementos confusos e dissociados, que podem ser compreendidos como uma mobilização defensiva perante a problemática do sofrimento.

Devido às atuais condições do mundo e da sociedade, espera-se que o indivíduo dê conta e domine muitas instâncias diferentes de sua vida. O fato é que ninguém os orienta sobre como fazer e ele não aprendeu que o sofrimento é inerente ao viver. Ele tenta dar conta, mas na pressão de ser "saudável" e "normal", adoece (Hortência).

Nesse campo de sentido, aparece outro aspecto relevante referente à existência de uma figura humana dissociada, presente no desenho de Hortência. Sobre esse aspecto, Figueiredo (2001) afirma que o sujeito atual é estruturado em dissociações e constituído pela multiplicidade de eus. A vivência e o reconhecimento do mundo como invasivo e, ainda, os constantes ataques sofridos podem levar o ser humano a dissociações do eu e ao enfraquecimento de suas fronteiras, na tentativa de se defender e tentar se organizar da ameaça de aniquilamento.

\section{Conclusão}

Por meio do uso do PDE-T em entrevista grupal para a abordagem da pessoalidade coletiva, com base em uma análise psicanalítica, coletaram-se elementos teórico-clínicos capazes de possibilitar reflexões sobre as condições contemporâneas e os novos modos de subjetivação. Os resultados alcançados possibilitaram identificar o imaginário coletivo sobre o sofrimento psíquico contemporâneo de estudantes ingressantes e de estudantes do último ano de um curso de graduação em Psicologia. Com base em estudos de Aiello-Vaisberg e nos resultados obtidos no presente estudo, identifica-se que os alunos iniciantes mostram-se mais espontâneos e sintonizados com o sofrimento humano, bem como mais livres do vazio representacional referente ao sofrimento e ao campo psicopatológico. Ao ingressarem no curso, dispõem de certas concepções simbólicas sobre questões eminentemente humanas, enquanto os alunos do último ano apresentam manifestações imaginativas que se caracterizam pela constituição da experiência subjetiva associada mais restritivamente ao conhecimento acadêmico adquirido. Nas produções de ambos os grupos de estudantes, nota-se o predomínio de campos amplos, nos quais emergem subcampos essencialmente vinculados entre si. 
Os resultados obtidos permitem apreender os sentidos subjetivos do sofrimento psíquico contemporâneo no imaginário coletivo dos estudantes participantes. Independentemente do momento acadêmico em que se encontram, as manifestações simbólicas dos dois grupos de estudantes correspondem, da mesma forma, a imaginários coletivos. Ambas são criações humanas sobre o sofrimento psíquico atual e expressam as peculiaridades e modalidades de sofrimento que se configuram no mundo de hoje.

O conjunto das análises permitiu a apreensão de um imaginário coletivo no qual o sofrimento é constituído, essencialmente, por sensações de solidão, desamparo, angústias, impotência, futilidade, irrealidade, inautenticidade e vazio existencial. Os resultados encontrados mostram-se coerentes com a literatura atual discutida, revelando as características e particularidades das modalidades de sofrimento psíquico na atualidade. Sugerem, ainda, reflexões e questionamentos acerca da influência da formação acadêmica no fenômeno investigado, com suas possíveis repercussões na prática clínica dos futuros profissionais. A ausência de um acompanhamento pormenorizado da evolução dos sentidos subjetivos atribuídos ao sofrimento psíquico nos dois grupos de estudantes, que poderia ser efetivado por um estudo prospectivo, revela-se um limite do presente estudo. Sugere-se a realização de novos estudos que possam aprofundar a compreensão das modalidades de sofrimento psíquico presentes na atualidade em diferentes perspectivas e grupos populacionais, especialmente os que fazem e farão emergentes na clínica da contemporaneidade.

\section{Referências}

Aiello-Vaisberg, T. M. J., \& Machado, M. C. L. (2003). Sofrimento humano e estudo da "eficácia terapêutica" de enquadres clínicos diferenciados. In T. M. J. Aiello-Vaisberg \& F. F. Ambrosio (Orgs.). Cadernos Ser e Fazer: apresentação e materialidade (pp. 6-35). São Paulo: Instituto de Psicologia da Universidade de São Paulo.

Aiello-Vaisberg, T. M. J., \& Machado, M. C. L. (2005, novembro). Narrativa: o gesto do sonhador brincante. Trabalhos do Encontro Latino-Americano dos Estados Gerais da Psicanálise, Rio de Janeiro, RJ, Brasil, 4.

Aiello-Vaisberg, T. M. J., \& Medeiros, C. (2010). Acordes do sofrimento humano. Contextos Clínicos, 3(2), 97-105.

Bauman, Z. (1998). O mal-estar da pós-modernidade (M. Gama \& C. M. Gama, Trad.). Rio de Janeiro: Jorge Zahar.

Birman, J. (2013). "Sujet et pouvoir dans la contemporanéité". Sur la souffrance et la douleur dans les formes de subjectivation. Recherches en Psychanalyse, 15, 11-22.

Bleger, J. (1989). A psicologia da conduta (2a ed.). (E. de O. Diehl, Trad.). Porto Alegre: Artes Médicas. (Obra original publicada em 1963).

Cambuí, H. A. (2013). Sofrimento psíquico contemporâneo: um estudo psicanalítico do imaginário coletivo de estudantes de psicologia. Dissertação de mestrado, Universidade Estadual Paulista. Faculdade de Ciências, Bauru, SP, Brasil. 
Campuzano, M. (2009). A pós-modernidade e suas influências nos indivíduos, nos conjuntos sociais, na psicopatologia e na psicanálise. Vínculo, 6(1), 65-78.

Dantas, M. A. (2009). Sofrimento psíquico: modalidades contemporâneas de representação e expressão. Curitiba: Juruá.

Figueiredo, L. C. (2001). Modernidade, trauma e dissociação: a questão do sentido hoje. In B. Bezerra Jr. \& C. A. Plastino (Orgs.). Corpo afeto linguagem - a questão do sentido hoje (pp. 219-244). Rio de Janeiro: Rios Ambiciosos.

Herrmann, F. (1979). Andaimes do real: o método da psicanálise (3a ed.). São Paulo: EPU.

Libermann, Z. (2010). Patologias atuais ou psicanálise atual? Revista Brasileira de Psicanálise, 44(1), 41-49.

Magdaleno, R., Junior (2010). Os novos ritmos do século XXI e a clínica psicanalítica contemporânea. Revista Brasileira de Psicanálise, 44(2), 101-109.

Menezes, L. S. de. (2008). Desamparo. São Paulo: Casa do Psicólogo.

Pires Caniato, A. M., \& Vargas Nascimento, M. L. (2010). A subjetividade na sociedade de consumo: do sofrimento narcísico em tempos de excesso e privação. Arquivos Brasileiros de Psicologia, 62(2), 25-37.

Pontes, M. L. da S., Barcelos, T. F., Tachibana, M., \& Aiello-Vaisberg, T. M. J. (2010). A gravidez precoce no imaginário coletivo de adolescentes. Psicologia: Teoria e Prática, 12(1), 85-96.

Saad, A. A. C. (2011). Da delicada complexidade do encontro analítico. Revista Brasileira de Psicanálise, 45(3), 41-50.

Winnicott, D. W. (1975). A localização da experiência cultural. In D. W. Winnicott. O brincar e a realidade (pp. 133-143). (J. O. de A. Abreu \& V. Nobre, Trad.). Rio de Janeiro: Imago. (Obra original publicada em 1967).

Winnicott, D. W. (1994a). O medo do colapso. In D. W. Winnicott, R. Sheppherd \& M. Davis (Orgs.). Explorações psicanalíticas: D. W. Winnicott (pp. 70-76). (J. O. de A. Abreu, Trad.). Porto Alegre: Artes Médicas. (Obra original publicada em 1963).

Winnicott, D. W. (1994b). O jogo do rabisco. In D. W. Winnicott, R. Sheppherd \& M. Davis (Orgs.). Explorações psicanalíticas: D. W. Winnicott (pp. 230-243). (J. O. de A. Abreu, Trad.). Porto Alegre: Artes Médicas. (Obra original publicada em 1964).

Winnicott, D. W. (2000). Aspectos clínicos e metapsicológicos da regressão no contexto analítico. In D. W. Winnicott. Da pediatria à psicanálise: obras escolhidas (pp. 374-392). (D. Bogomoletz, Trad.). Rio de Janeiro: Imago. (Obra original publicada em 1954). 